\section{$\underset{\substack{\text { hommes } \\ \text { \& migrations }}}{ }$}

\section{Hommes \& migrations}

Revue française de référence sur les dynamiques

migratoires

$1319 \mid 2017$

Réfugiés et migrants au Liban

\title{
Maryam Madjidi, Marx et la poupée
}

Paris, Le nouvel Attila, 2016, 225 p., $18 €$.

\section{Mustapha Harzoune}

\section{(2) OpenEdition}

\section{Journals}

\section{Édition électronique}

URL : http://journals.openedition.org/hommesmigrations/4026

DOI : 10.4000/hommesmigrations.4026

ISSN : 2262-3353

\section{Éditeur}

Musée national de l'histoire de l'immigration

\section{Édition imprimée}

Date de publication : 1 octobre 2017

Pagination : 194-195

ISBN : 978-2-919040-39-1

ISSN : $1142-852 X$

Référence électronique

Mustapha Harzoune, "Maryam Madjidi, Marx et la poupée », Hommes \& migrations [En ligne], 1319 |

2017, mis en ligne le 01 octobre 2017, consulté le 07 janvier 2021. URL : http://

journals.openedition.org/hommesmigrations/4026 ; DOI : https://doi.org/10.4000/

hommesmigrations.4026 


\section{LIVRES}

din, l'autrele souvenird'un amant, la dernière un Etdorado.

Ee roman, d'une riche densité thématique, scrute les grandeurs et les petitesses de la nature humaine, le devenir te la Nature et de l'humanité quand t'homme se veut démiurge et prétend "changertedévetoppement desespèces". te récit, souvent bouleversant, est écrit sans pathos. Implacable. Presque froid; en apparence du moins. Carla rareté des adjectifs et des adverbes renforce l'effet des descriptions, tes dynamiques psychologiques, l'empathie et les émotions. Fout est dur mais pas sans espoir. Il faudrabienne plus craindre "ce quise cache dans la nuit du coeur humain ". Et aller vers ce "pays où les arbres nont pas t'ombre"

M. H.

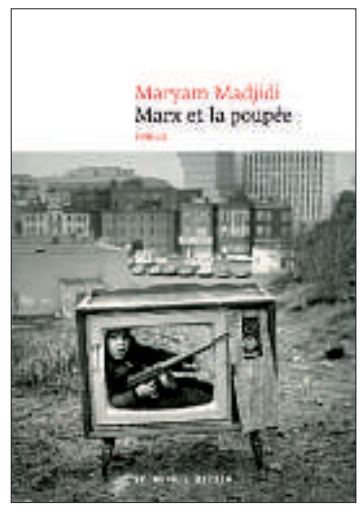

\section{Maryam Madjidi} Marx et la poupée Paris, Le nouvel Attila, 2016, 205 p., $18 €$.

Voici une nouvelle venue dans les lettres françaises. Nouvelle venue dont la trajectoire croise celle de milliers d'autres, élargit les horizons de chacun, mais dont le silIon reste personnel. On peut se rattacher à un ou plusieurs récits collectifs, et cultiver quelques singularités. L'identité, cette alchimie mouvante, syncrétique et peut-être insaisissable, passe par le filtre des émotions intimes et des expériences. Et les mots traduisent toutes les sensibilités, projettent sur le monde autant d'éclairages et de variations. De renaissances aussi.

Pas de simagrées ici, de simulacres ou de poses. Le propos claque la porte au nez des sots et des condescendants, comme aux petits manitous des ordres identitaires et des idéalisations hors sol.

Le livre est une dense méditation sur l'exil. Le couple et leur fille débarquent d'Iran, ils pourraient venir d'ailleurs tant le sujet est universel, les expériences et les enseignements transposables. Maryam Madjidi raconte par petites touches, en cours chapitres, rythmés par trois "naissances". Le poème final donne une idée de la structure: "Souffle / souffle / Vent de ma vie / Souffle / souffle / Et fais danser les souvenirs".

Cet archipel de souvenirs qui courent depuis l'enfance finit par former un collier de variations, et de contrepoints voir l'art d'être persane ou français, l'épisode des croissants, le méli-mélo des langues, le traquenard " orientaliste " et comment se jouer des charlots, le jeu de miroir entre un Iran fantasmé et une France "jamais idéalisée". Le tout dévoile la finesse du propos derrière une rudesse affichée; non sans raison. Car, en matière d'exil, il faut secouer le cocotier-comme ne dirait pas la subtile iranienne - histoire de faire tomber les bonimenteurs haut perchés, pour comprendre que si l'on veut vivre, il faut partir ! II faut enterrer ses poupées, des livres par trop compromettants et ses rêves. Pour sentir comment une mère peut «se diluer silencieusement dans une eau imaginaire". Pour voir l'exil à travers les mains d'un père, des mains qui finissent par ne plus bouger, parce qu' "elles se 
sentent coupables ». Comprendre aussi pourquoi Maryam Madjidi « déterre les morts en écrivant ». Ces morts, ce sont les combattants de la liberté, héritiers d'un Hafez qui invitait à ne pas tomber « dans le piège de l'hypocrisie comme ceux-là qui ont sali le Coran ».

Et puis il y a la France. "Je voudrais me taire quand on me demande mes origines. Je voudrais raconter autre chose, n'importe quoi, inventer, mentir. Je voudrais aussi qu'on me pose d'autres questions inattendues, déroutantes, mêmes absurdes, qu'on me surprenne. Et en même temps,je me vautre dans mon petit monde exotique et j'en tire une fierté jouissive. La fierté d'être différente. Mais toujours cette petite voix intérieure qui me rappelle que tout ça ce n'est pas moi, que je me cache derrière un masque, celui de l'exilée romanesque. Je vous le donne ce masque, prenez-le, je le dépose entre vos mains. " Et les masques tombent, à commencer par celui de la "douleur refoulée "-on pense à Doan Bui. Ces cauchemars et ces dessins terrifiants d'une enfant, d'une « survivante ». Ses combats (et ses victoires) à l'école et comment il fallut "avaler sa langue " pour triompher dans «la langue des Lumières et de Molière ». Plus tard, la femme toujours hantée par quelques fantômes, continuera d'entendre la voix consolatrice et résiliente, de sa grand-mère.

Il faut aussi passer "d'un monde à l'autre, d'une langue à l'autre » et "jongler avec les identités ». Il est juste alors de rabattre le caquet de ceux pour qui la double culture est une richesse quand on " vacille tout le temps, d'un bord à l'autre " et d'être " en colère contre ces hypocrites qui s'extasient sur une blessure ». Faute du bon outillage conceptuel, la «blessure" peut faire "glisser sur son identité ». Et «tomber»! Comme lors de ce premier retour à Téhéran où la jeune femme a risqué de "briser toutes les colonnes de sa vie». Un livre à mettre entre les mains de tous les gamins de France. Et de quelques caciques encore perchés.

M. H.

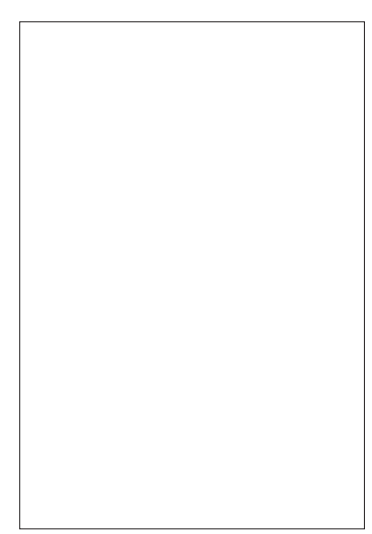

des chemins, des trajectoires entrelaéés, des origines mêtées, des opinions

\section{Shumona Sinha} Apatride

Paris,éd. de L'Olivier, 2016, 188 p., 17,50€.

"Apatricte", le mot elaque et sa sécheresse dérange. À lui seul, it porte sa charge symbo= tique et son poids de préjugés. Mais, qu'estce qui fait, aujourd'hui, l'apatride? La croisée rebelles; ce qui retègue au "pas d'ici ", à l'" étrangeté ", l' "indocilité ", I' "utopique". Le "hors sol". Apatrides! tétrangère confrontée à une administra= tion suspicieuse, en butte aux idées reçues et hostiles. L'enfant adopté qui ignore tout de ses origines et de ses parents biologiques. L'indienne entraînée dans une lutte inégate contre des forces politiques etéconomiques alliées. Apatrides, dans ce monde d'hommes, ces femmes privées du droit d'exister et d'aimer.Nationalistesetcommunautaristes (hindouistes ou musulmans), égoïstes, racistes ou imbéciles, affameurs de pain 